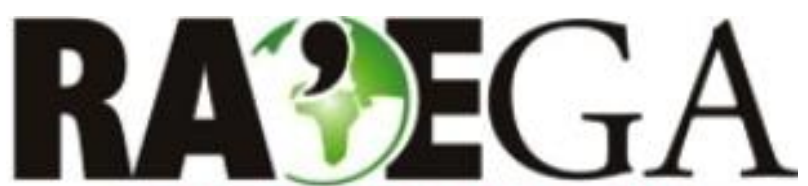

O ESPAÇO GEOGRÁFICO EM ANÁLISE

\title{
GEOSSISTEMA E COMPLEXIDADE: SOBRE HIERARQUIAS E DIÁLOGO ENTRE OS CONHECIMENTOS ${ }^{1}$
}

\author{
GEOSYSTEM AND COMPLEXITY: ABOUT HIERARCHY AND DIALOGUE BETWEEN THE KNOWLEDGE
}

\author{
Rodrigo Dutra Gomes², Antonio Carlos Vitte ${ }^{3}$
}

\section{RESUMO}

A construção da relação entre Geografia e Teoria da Complexidade ainda é incipiente em território nacional. Pretende-se dialogar alguns dos entendimentos da Teoria da Complexidade com a reflexão da noção de hierarquia e diálogo entre conhecimentos no Geossistema. Considerou-se o Geossistema como "Sistema Singular Complexo" e utilizou-se os textos clássicos de Sotchava e de Bertrand para os confrontos teóricos. Tal confronto traz importantes repercussões para a teoria e modelo Geossistema. Como resultado, pela Complexidade, o geossistema deixar de ser um fenômeno natural e objetivo, incluindo agora a arbitrariedade do pesquisador e pretensões da pesquisa para a sua delimitação. O humano e o natural não são vistos como antagônicos, mas pertencentes a uma mesma trama de relações complexas que envolvem multidomínios e escalas de manifestação. As escalas e as hierarquias do geossistema deixam de ser objetivas e passam a se referir a ritmos espaçotemporais de interação discernidos pelo pesquisador na multiplicidade dos processos espaciais. Concluiu-se que cada ritmo de interação entre elementos e forças detém sua própria e singular espaçotemporalidade, que varia de acordo com a natureza dos elementos e intensidade das trocas, podendo se referir à relações com espaçotemporalidades nas e pelas diversas escalas. 0 diálogo entre os conhecimentos vêm para lidar com esta multiplicidade de ritmos presentes e influentes nas e pelas escalas e domínios humanos e naturais.

PALAVRAS-CHAVE: Sotchava; Bertrand; Ritmos espaçotemporais; Sistema Singular Complexo.

\section{ABSTRACT}

The construction of the relationship between geography and Complexity Theory is still incipient in the national territory. The intention is connect the understandings of the Complexity Theory with the reflection of the Hierarchy notion in the conceptual-model Geosystem. The geosystem is considered as "complex singular system" and used the classic texts of Sotchava and Bertrand to the theoretical confrontations. This confrontation has important implications for the theory and geosystem model. As a result, by the Complexity Theory the geosystem is not a natural and objective phenomenon, now including the arbitrariness of the researcher and pretensions of the research for its delimitation. The human and the natural are not seen as antagonistic, but conjugated in the same web of complex relationships, involving multidomain and scales of manifestations. In the discussion about scale, as a result, the hierarchies in the Geosystem are not objective things, but spatiotemporal rhythms of interaction discerned by the researcher in the multiplicity of spatial processes. To was concluded, each rhytms of interaction between elements and forces has its own singular spacetemporality, which varies according to the nature of elements and nature of the exchange and intensity of the relationships in the different scales. The dialogue between the knowledge, methods come to deal with the multiplicity of domains and rhythms in human and natural scales.

KEY-WORDS: Sotchava; Bertrand; spatiotemporal rhythms; Complex Singular System.

Recebido em: 09/06/2016

Aceito em: 06/11/2017

\footnotetext{
1 Pesquisa Pós-doutorado Financiada pela FAPESP - Processo 2010/16105-8.

2 Universidade Federal do Pernambuco, UFPE, Recife/PE, e-mail: rdutragomes@gmail.com

3 Universidade de Campinas, UNICAMP, Campinas/SP, e-mail: acarlosvitte@uol.com.br
} 


\section{GEOSSISTEMA E COMPLEXIDADE: SOBRE HIERARQUIAS E DIÁLOGO ENTRE OS CONHECIMENTOS}

\section{INTRODUÇÃO}

Em 1984 foi realizado em Montpellier na França o primeiro evento internacional sobre o tema da Teoria e Ciência da Complexidade. Incluiu nomes como N. Luhmann, Le Moigne, $\mathrm{H}$. Atlan, E. Morin, I. Prigogine, K. E. Boulding, O. Costa de Beauregard, C. S. Holling entre outros. Buscaram discutir as consequências epistemológicas de conceitos como nãolinearidade, caos, auto-organização, emergência. Como eco das repercussões do evento, no mesmo ano foi criado o Instituto Santa Fé no Novo México nos Estados Unidos, com direcionamentos pragmáticos mais intensos, contudo, versando sobre muitos temas semelhantes, como interdisciplinaridade, modelagem, complexidade, emergência; mas dando destaque principalmente para a construção de ferramentas computacionais e simulação dos fenômenos para fins práticos (SHŪHEI, 1985, 384p.).

Para a Geografia, em território brasileiro, o contexto da Complexidade começou a ser destacado em textos como os de Christofoletti (1988, p.149) e Monteiro (1991, 233p.). Os autores já alertavam para a nova fase de incorporação, reinterpretação e diálogos que tal contexto traria para as reflexões do fenômeno geográfico. No mesmo período, pelas mesmas influências, Culling (1987, p.57, 1988, p.345) e Haigh (1987, p.181) já propunham novas interpretações, o primeiro principalmente para a Geografia Física pela noção de Equifinalidade, e o segundo discutindo as hierarquias escalares pela noção de Holon. Em 1992 a revista Geomorphology lança edição destacando a necessidade de incorporar os pensamentos e ferramentas da Complexidade, bem como rever entendimentos fundantes da Geomorfologia; como a noção de equilíbrio (PHILLIPS, 1992).

Desde o final do século $X X \quad a$ incorporação da Complexidade para o fenômeno geográfico tem sido cada vez mais intensa (MALANSON, 1999, p.746). Contudo, para o modelo-conceitual Geossistema quase não foram realizados estudos de confronto, diálogo e incorporação de entendimentos. Nesta direção, ao finalizar o relato de suas experiências na aplicação e avaliação crítica da abordagem geossistêmica no Brasil, Monteiro (2001, p.102) já colocava:

(...) antevejo que as condições futuras
de investigação científica são altamente
promissoras. Os progressos atuais na
análise dos sistemas altamente
complexos, a teoria do caos, e outros
avanços serão, com certeza, poderosos
meios de aprimoramento e avanços na
formulação teórica dos geossistemas.
(...) ao mesmo tempo que técnicas já
existentes e disponíveis para muitos
(...) são ferramentas indispensáveis ao
avanço dessas ainda incipientes mas
necessárias concepções destinadas às
novas geografias, sobretudo aquela do
futuro que se nos avizinha (MONTEIRO,
2001, p.102).

Nesta perspectiva, pretende-se oferecer um diálogo entre $\mathrm{o}$ modelo conceitual Geossistema e a Teoria da Complexidade; o foco será a reflexão sobre a Hierarquia e a necessidade do diálogo entre os conhecimentos. Nesta leitura serão utilizados somente os textos clássicos de Sotchava e de Bertrand, pois, enquanto contato inicial, constituem eles as principais referências clássicas das reflexões e aplicações nacionais. Georges Bertrand será tratado pelos seus textos clássicos, como a Paisagem e Geografia Física Global. Assim, as discussões mais recentes dos textos traduzidos do autor em Bertrand \& Bertrand (2002, 361p.), com sua proposta GTP (Geossistema-TerritórioPaisagem), será discutido em outro artigo específico que posteriormente será publicado. Para o diálogo e incorporação de entendimentos, a proposta de Monteiro (1978, 43p., 1987, 48p., 2001, 127p.) será utilizada como referência de concepção de Geossistema, visto que já foi observado (DUTRA-GOMES, 2012,, 368p.) que apresenta importantes congruências com os entendimentos atuais da Complexidade.

Esse diálogo foi realizado a partir da análise e posterior confronto das propostas geossistêmicas com os entendimentos da 
Complexidade. A análise foi feita a partir do discernimento das proposições sobre hierarquia e escala no contexto da Complexidade e das concepções Geossistemicas de Sotchava, Bertrand e Monteiro. Tomando-se cuidado para não isolar estas noções do conjunto de cada proposta, buscou-se discernir as especificidades dos argumentos que cada uma carrega. O confronto foi realizado de forma lógica, destacando as repercussões diretamente perceptíveis em termos definição e manifestação escalar e interrelação entre os níveis. Neste movimento, a discussão sobre a necessidade de diálogos entre os conhecimentos no Geossistema vem como uma das decorrências advinda deste confronto. Mesmo não sendo o foco principal, a discussão também remete ao problema da incorporação do humano e sociedade no modelo.

O texto inicia com uma breve contextualização da relação Geografia e Complexidade; com respeito às propriedades dos sistemas complexos sobre escala e hierarquia, bem como algumas repercussões já pensadas na Geografia. Em seguida foi apresentado a discussão sobre hierarquias e escalas na proposta de Monteiro (1978), bem como, logo depois, nas propostas clássicas de V. B. Sotchava e G. Bertrand. Na última parte do texto houve, então, o confronto direto entre as concepções, reinterpretando algumas considerações geossistêmicas pelos entendimentos advindos da Complexidade.

\section{RESULTADOS E DISCUSSÕES}

GEOGRAFIA E TEORIA COMPLEXIDADE: APROXIMAÇÕES AINDA RECENTES.

As teorias sistêmicas (Teoria Geral dos Sistemas-TGS, Cibernética e Teoria da Informação), tão presente na Geografia pós década de 50, são consideradas os pilares da Teoria da Complexidade (MORIN \& LE MOIGNE, 2000, 263p.). Desenvolvimentos científicos ocorridos na segunda metade do século XX encorparam a perspectiva sistêmica $e$ forneceram os elementos para o que depois se constitui como o contexto da Complexidade (Teoria e Ciência). Os avanços na ciência em campos como os Sistemas Dinâmicos Nãolineares e Física do Não-equilíbrio, Teoria da Linguagem, Cibernética, Biologia associado à um panorama nas ciências humanas de destaque das contradições sociais, particularidades locais, imaginário do sujeito e incertezas econômicas, nutriu-se um contexto reflexivo que convergiu no que se denominou de Complexidade (Teoria e Ciência). Esse contexto envolve tanto um aparato técnico científico (de métodos, modelagem e técnicas), representado pelo Instituto Santa Fé (EUA), quanto reflexões filosóficas em figuras como Morin (2002, 480p.), Prigogine \& Stengers (1991, 247p.), Morin \& Le Moigne (2000, 263p, 2009, 527p.). Embora discerníveis, e com certas autonomias, a Teoria e Ciência da Complexidade dão destaque às mesmas propriedades dos sistemas complexos (como não-linearidades, emergências, auto-organização, criticalidades).

No conhecimento científico os denominados Sistemas Dinâmicos Complexos e a Teoria da Complexidade são as expressões conceituais mestras do contexto que reconheceu o objeto do conhecimento como uma entidade complexa. Neste sentido, não há uma "Teoria da Complexidade" de proposição acabada e fechada, em um livro ou autor, mas sim representa um contexto de entendimentos que versam sobre temas comuns. Seus entendimentos vieram na contra-mão das crenças dos princípios fundantes da ciência no XVII e XVIII, cuja pretensão tinha a simplicidade, regras, leis, estabilidade, ordenação, hierarquias rígidas como governantes do funcionamento do mundo e conhecimento. Tal questionamento é repercussão do reconhecimento, desde o fim do século XIX, e acelerado e afirmado no $X X$, das nãolinearidades, desordens, singularidades como inerentes ao conhecimento e funcionamento do mundo, associados à noções como emergência, auto-organização, incertezas, caos, desequilíbrios, turbulências, bifurcações, quebras de simetria, catástrofes, rupturas etc.

Em diálogo a essas noções, o caráter 'complexo' caracteriza-se basicamente por ser algo composto da inter-relação de muitas partes (ou elementos), processos e padrões variados, 
havendo ainda, em noções como emergência, o surgimento de novas organizações a partir das interações internas do sistema. Estas organizações manifestam-se em outras escalas diferente da dos elementos, e estabelecem comportamentos em relação ao ambiente que não estão na escala das partes-indivíduos. Isso destaca a existência e interação entre domínios (esferas de ações) e dimensões (escalas) não redutíveis, nem em manifestação, nem em entendimento uns aos outros. Diferente da concepção moderna que destaca as regras e padrões, na descrição em termos de sistemas complexos as relações internas do sistema são fundamentais para o entendimento de sua dinâmica, bem como do surgimento de novas organizações em termos de totalidades a partir destas relações; manifestadas em outras escalas, e estabelecendo comportamentos que não estão na escala das partes-indivíduos.

Esse é o mesmo movimento de transição de uma concepção de Mundo mecânica e estática para uma orgânica e processual (PRIGOGINE, 1989, p.396-400). Para sintetizar, de acordo com Morin (1985, p.62-68), o principal problema trazido pela Complexidade é a incompletude do conhecimento, a incompletude de qualquer método, teoria, abordagem querer conseguir sozinhos (monisticos) abarcar a realidade, exigindo a construção de formas mais flexíveis e dialógicas para lidar com os diversos conhecimentos. Concepção monística que a Ciência buscou desde o século XIX ser a principal representante.

As aproximações entre Complexidade e Geografia vêm ocorrendo principalmente a partir das últimas décadas do final do século XX e início do XXI, trazendo importantes repercussões em suas diversas subdisciplinas e temáticas (SCIENCE, 1999, 1-212, MALANSON, 1999, p.746753). Envolve tanto a incorporação das ferramentas e modelagens, como os modelos Agent-based (CLIFFORD, 2008, p.675-686), quanto as reflexões teóricas. Dentre as repercussões já notadas as dualidades e fundos dicotômicos persistentes (ex. natureza/cultura), se dissolvem e fluem numa perspectiva organizacional, sem perder suas distinções e legitimidades. A construção do espaço geográfico, neste contexto, independente das diversas definições, se dá por multi-domínios e dimensões, mutuamente influentes e generativos, mas que não são redutíveis nem em manifestação (ontológico), nem em entendimento (epistemológico) uns aos outros, exigindo, a necessidade de dialogar formas de conhecimentos (teorias, métodos, epistemologias, técnicas) (DUTRA-GOMES, 2009, p.119). O panorama é de diálogos e comunhões entre as formas de conhecimentos antes pautadas no dual, e busca de "terceiras" vias e proposições. Estabelece-se uma tensão criativa de diálogos e comunhões entre ciências/humanidades, explanativo/interpretativo, espaço/lugar (DUTRA GOMES, 2010, p.219-230), e que repercute tanto na temática da Geografia Humana (O'SULLIVAN, 2004, p.282-295, DUTRA-GOMES \& VITTE, 2014, p.89-130), quanto da Geografia Física (DUTRAGOMES \& VITTE, 2011, p.08-38). Nesta direção de diálogos e enriquecimentos da relação entre Teoria e Ciência da Complexidade e Geografia torna-se necessário buscar estabelecer aproximações entre entendimentos e sentidos.

A mesma situação de diálogos se estabelece quando considera-se o problema da escala pela Complexidade. Isso considerando a capacidade de pequenas interações locais ganharem repercussões globais e em grandes áreas (RUELLE, 1993, 224p.); considerando também a propriedade emergêncial presente em cem número de interações, que faz emergir uma novidade qualitativa à nível da totalidade e cuja característica é a não redutibilidade, nem manifestação nem em entendimento às interações ocorridas ao nível das partes; ideia corroborada pela teoria sinergética de Haken (1982) tendo como exemplo, a cidade em relação às casas, lojas, ruas, ou o trânsito sobre os carros individuais. Temos ainda a considerações trazida pelos Fractais com os ruídos aleatórios que caracterizam as perturbações de transmissão de informação num sistema dinâmico apresentandose como proporcionalmente constantes pelas 
diversas escalas - como é o caso da expansão urbana (TRENTIM \& FERREIRA, 2015, p.198) .

Uma discussão ampla sobre escala geográfica e Teoria da Complexidade ainda precisa ser realizada; no presente caso, focaremos sobre a temática da escala, pela hierarquia, no modelo Geossistema. Pela Complexidade, as hierarquias entre as escalas parecem deixar de ter limites rígidos e passam a ser vistas em termos de condicionamentos das partes na manutenção de uma totalidade espaçotemporal relacional. As interações entre as diversas escalas (como níveis de condicionamento das interações), ficam mais fluidas e podem se influenciar. Apesar da legitimidade da diferença de grandeza espacialmétrica e dos diferentes processos ocorrendo nas diversas escalas, as interações à nível do local e do global se interpenetram sem imposições tão rígidas uns sobre os outros.

As hierarquias deixam de ter manifestação fixa e, ainda que discerníveis, se tornam puramente relacionais, descritas mais em termos de organização do que de hierarquia, tendo nomes e classes apenas como fruto dos discernimentos do sujeito - das relações por ele focada, e que darão os tons dos discernimentos das organizações e das possíveis influências por entre as escalas. Neste sentido, como exemplo, mesmo que as emergências sejam legítimas em termos de manifestação escalar, por um lado seus limites não são rigidamente estabelecidos, e, por outro, as relações focadas pelo problema da pesquisa não necessariamente precisa destacar todas as emergências; e sim as relações e emergências pertinentes para aquele problema.

Manson (2008, p.776-788), apoiado na Complexidade, mas com base numa abordagem construtivista chega a semelhante conclusão, destacando o 'continnum escalar' que se estabelece ao desconsiderar a mediação do sujeito-social, ou seja, quando a escala é vista independente do observador. Entendimento que não se restringe às ciências físicas, a própria Sociedade Informacional, mesmo com as imposições geopolíticas, territoriais e culturais, também demonstra a não rigidez entre as hierarquias e fixações das escalas de análise na experiência espacial contemporânea. As movimentações sociais de 2014 aqui no Brasil é um bom exemplo, com o local e o global se interpenetrando e se modulando mutuamente naquela situação quando indivíduos não-lideres organizaram passeatas à partir da agilidade das trocas de informação pelas redes sociais na internet. Foi justamente o caráter de rede e agilidade de trocas de informações que não possibilitou a formação de líderes e centros gestores definidos. As passeatas ganharam repercussão global (em todo o país), caracterizada justamente pela heterogeneidade de temas num movimento de reivindicação comum. Assim, é um bom representante de tal interpenetração escalar. A abordagem construtivista discutida por Manson também é a mesma de Maturana e Varela (2001), que já utilizamos para discutir a concepção de sujeito da Teoria da Complexidade e algumas de suas repercussões na construção do espaço geográfico (DUTRA-GOMES, 2009, p.109-122).

Pelos termos da Complexidade, a ideia de historicidade, ligada a ideia de espaçotemporalidade, em sua vinculação com o fluxo unidirecional energético (Energia Livre $\rightarrow$ Entropia) traz a partir da noção de entropia uma importante condição de união, discernimento e fluidez entre as escalas e os domínios de manifestação legítimos nos coexistentes sistemas espaciais (DATTA \& RAUT, 2006, p.581-589). Ou seja, em termos físicos, o fluxo de produção de entropia que uni as escalas numa conjunta dissipação de energia (neste sentido temporal), também uni as escalas espaciais. Também em termos informacionais a definição de complexidade em relação ao nível de informação de um sistema complexo esclarece, no mesmo sentido das interações causais, a fluidez e influência das informações (com ruídos e redundâncias) espaciais pelas e nas diversas escalas (por exemplo, os fractais).

As manifestações escalares são confirmadas como legítimas, mas se tornaram muito mais fluidas e inter-influentes. Isso não 
apenas para expressões espaciais como os fractais, mas com respeito às atitudes humanas, que, com base na interpretação simbólica da informação, a nível local, podem influir e perpassar pelas escalas macro, que antes eram tidas como imperantes. Ou seja, na esteira da interpretação da Complexidade, o indivíduo, ou comunidade, por exemplo, não são marionetes de uma dinâmica universal que impõe uma conduta, mas, seguindo os entendimentos da Complexidade, possuem a capacidade de tanto influenciar os processos tidos como universais em escala macro, quanto gerá-los a partir da natureza de suas interações locais.

Assim, em meio ao emaranhado de intricadas interconexões e influências pelos diversos níveis de matéria, energia e informacão, e, considerando o discernimento arbitrário (do sujeito), um sistema deixa de ter escala de manifestação rígida como definida em seu sentido tradicional. Nesta situação, Chapura (2009, p.462-474) destacou a importância de uma análise poliescalar para o estudo geográfico. Para evitar os reducionismos, o discernimento do sujeito poderia ser, de acordo com o autor, auxiliado a partir da revalorização das categorias da causalidade - formal, final, material e eficiente - que, dialogando uma com as outras, ajudariam a escolha e definição sobre a natureza das interações e manifestações consideradas; ajudando na escolha dos melhores métodos. Nesta direção, foi para auxiliar os discernimentos do sujeito e descrição da dinâmica que a noção de Ritmo tornou-se adequada no estudo dos sistemas complexos. Noção também destacada, em âmbito nacional, por Monteiro (1991, 233p.); ainda que pouco tenha sido usada para a sua concepção de Geossistema, e que aqui será retomada.

\section{A CONCEPÇÃO GEOSSISTÊMICA DE REFERÊNCIA: O "SISTEMA SINGULAR COMPLEXO"}

Na proposta de Monteiro (1978, 43p.) e usada por Penteado-Orellana (1985, p.125-148) o Geossistema foi tratado como conceito operacional, entendido como um 'Sistema Singular Complexo'. Os direcionamentos conceituais e metodológicos procuraram elaborar tratamentos a partir do confronto de modelos paralelos - um para aos sistemas físico-naturais e outro para aos sistemas sócio-econômicos. A modelização baseou-se numa unidade (não uniformidade) teórico-metodológica que considerou o homem como 'derivado' do dinamismo de massas, energia e informação da Natureza - entendimento semelhante ao da Complexidade. O humano emergente no social, com suas dinâmicas culturais e econômicas, não é considerado conceitualmente antagônico e oponente ao equilíbrio da natureza, mas, sim, incluídos todos no funcionamento do próprio sistema. Monteiro (1978, p.61) esclareceu que, tratar a partir de modelos paralelos não sugeriria, nesta proposta, uma fragmentação de análise, mas, ao contrário, visava dar flexibilidade de articulação para um melhor entrosamento de informações, aumentando a confiabilidade dos dados obtidos, conjugados pelo complemento mútuo de dados (MONTEIRO, 2001, p.53-56, PENTEADO ORELLANA, 1985, p.131). Essa proposta de diálogos complementares em modelos paralelos também entra em sintonia com a perspectiva dialógica da Complexidade, de diálogo entre as diversas formas de conhecimentos - com respeito ao reconhecimento das legitimidades e nãoredutibilidades de inúmeros fenômenos, como as emergências.

A necessidade desse tratamento conjunto pode estar associada à própria limitação representativa da perspectiva analítica que oculta, nos estudos ambientais, pertinentes fatores do movimento processual, principalmente os ligados aos fenômenos humanos. A distinção entre modelos sócioeconômicos e físico-naturais vem, assim como esforço para o reconhecimento das especificidades da manifestação humana, que sujeitam, em nível cultural-sócio-políticoeconômico, mudanças deliberadas nos sistemas ambientais. $O$ recorro a procedimentos qualitativos, como entrevistas sobre a percepção, o mundo vivido e aspectos sociais e econômicos dos indivíduos e grupos, pela aplicação de 
questionários ou conversas, requerem inquéritos, por vezes, mais maleáveis e interpretativos do que a abordagem sistêmica atualmente propõe. Essas dificuldades exigem não somente que se destaque a necessidade de melhor aprendizagem das abordagens comumente praticadas, mas também a realização de trabalhos em equipes, que, por sua vez, requerem significativos esforços de abertura e aceitação por entre os pesquisadores. Há ainda a necessidade de esclarecimentos teóricos que promovam os 'locais de diálogos' que embasem as complementaridade e conciliações; isso como forma mesmo de se propor encaminhamentos operacionais que busquem e ofereçam resultados mais harmônicos no estudo das relações sociedade/natureza. Para o geossistema isso direciona para uma melhor capacidade de tratamento de áreas fortemente humanizadas como as urbanas.

Sobre a escala, nas propostas europeias (russa e francesa) o modelo conceitual Geossistema carregou influência da concepção mecanicista de totalidade e do naturalismo do pensamento científico moderno, principalmente via positivismo e neopositivismo. A totalidade seria uma das formas de se reportar a universalidade das leis científicas. Elas existiriam de forma objetiva e seriam uma das expressões do universal, que exerceriam influências hegemônicas, pelas leis científicas, sobre o funcionamento das partes. O naturalismo, por sua vez, seria a matriz de funcionamento e conhecimento do mundo. Defendia o reducionismo de que todos os fenômenos operariam de acordo com as leis estudadas pelas ciências físicas-naturais (Física, Química, Biologia), e por isso, todos os fenômenos inclusive, os humanos (sociais e culturais), deveriam ser estudados a partir dos métodos destas ciências naturais, com este sendo o único e melhor modelo de ciência a ser seguido.

$$
\text { Em Sotchava (1977, p.06-09) o }
$$

Geossistema é uma totalidade objetiva e um fenômeno natural, para Bertrand (1972, p.127133), embora com diferenças notáveis na inserção dos fatores antrópicos, tais propriedades de totalidade objetiva e natural também consta. Na proposta de Sistema Singular Complexo de Monteiro (1978, 43p.), e PenteadoOrellana (1985, p.125-148), o Geossistema não é uma totalidade objetiva, mas uma definição espacial arbitrária, de acordo com os objetivos e interesses do pesquisador.

O Geossistema é um sistema singular complexo onde interagem elementos humanos, físicos, químicos e biológicos e onde os elementos sócio-econômicos não constituem um sistema antagônico e oponente, mas sim estão incluídos no funcionamento do próprio sistema. (...) é possível determinar os seus limites partindo das relações dos elementos sociais entre si e desses elementos com o meio. Outro ponto inovador é a possibilidade de defini-lo abstratamente, desde que o pesquisador ou o grupo identifiquem as relações que eles querem analisar (...) (PENTEADO-ORELLANA, 1985, p.131).

Assim, não há a adesão a tais sentidos de imposições totalitárias e naturalistas. Mas, num tom de proposta de avanço da concepção e análise, insere o fator sócio-cultural e as arbitrariedades, tanto no caráter fenomenal das totalidades (ontológico), que se tornam relacionais, quanto de entendimento (epistemológico) do Geossistema. Monteiro (1978, p.45) apenas discerne, mas não separa, a dinâmica humana a da natureza, não limitando o primeiro a ser um fator de desequilíbrio dos sistemas naturais, como por ex. fez Sotchava (1977, 52p.), mas, como parte integrante, podendo também responder por processos benéficos e regeneradores do sistema:

Minhas preferências pessoais procuram evitar a consideração das relações entre natureza e sociedade em termos de antagonismo entre sistemas oponentes. Antes, procuro encará-lo dentro da perspectiva (embora incômoda à análise) de um sistema singular, de tipo complexo, evolutivo e cibernético. O homem-parte integrante 
da natureza - tende (não sem razão) a ser visto como o "vilão", responsável pela destruição da natureza. Será necessário conceder-Ihe o crédito de confiança (e há também razões para tal) de que ele pode e deve ser capaz de introduzir circuitos positivos de "feedbacks" regeneradores e autoreguladores do sistema (MONTEIRO, 1978, p.45).

\section{O GEOSSISTEMA PELA COMPLEXIDADE: A FLUIDEZ HIERARQUICA E O DIÁLOGO ENTRE OS CONHECIMENTOS}

A hierarquia parece ser um dos aspectos mais característicos e importantes da conceituação do Geossistema, contudo, nota-se também que foi um dos menos detalhados e aprofundados. Embora haja a classificação dos níveis escalares de análise, suas unidades, dimensões, pouco se falou sobre o funcionamento e as influências entre os níveis. Nas "bases lógicas do estudo de geossistemas" Sotchava (1977, p.09) destacou de início:

Geossistemas - são uma classe peculiar de sistemas dinâmicos abertos e hierarquicamente organizados (Bertalanffy, 1973) (...). Hierarquia de construção é a mais importante feição dos geossistemas. Devido a isso, tanto a área elementar da superfície da Terra, quanto o geossistema planetário ("geographical cover"), ou as subdivisões intermediárias do meio natural representam (cada qual separadamente ou em conjunto) uma unidade dinâmica, com uma organização geográfica a ela inerente. A última manifesta-se em espaço que permite a distribuição de todos os componentes de um geossistema, assegurando sua integridade funcional. Um geossistema não se subdivide ilimitadamente: as unidades espaciais acham-se na dependência da organização geográfica. (...) Toda categoria dimensional de geossistema (topológica, regional, planetária e intermediárias) possui suas próprias escalas e peculiaridades qualitativas da organização geográfica (SOTCHAVA, 1977, p.09-10).

As divisões escalares parecia respeitar as funcionalidades das totalidades, de forma que ficava sub-entendido interações entre as hierarquias, mas a sua descrição era feita em termos de unidades homogêneas de acordo com escala, sem que houvesse o aprofundamento nos mecanismos de interação entre elas. Mas observou-se em Sotchava (1977, p.22) um sentido de subordinação funcional das unidades elementares, dos geótopos, para com as unidades de ordem escalares de maiores dimensões, geócoros e geomas regionais; embora não seja claro quais são os níveis e os jogos de intensidades destas subordinações e das retroações advindos do local:

(...) será desnecessário dizer que essa rotação elementar de substância, expressa na unidade espacial mínima de um local com determinado fácie, só pode ser considerado como parte hierarquicamente subordinada de outra rotação, de maior raio de atividade, a qual, por seu turno, achase também subordinada à rotação da categoria seguinte, segundo um volume crescente de metabolismo (SOTCHAVA, 1977, p.22). (...) Subcontinentes são divididos em megaposições (grupos de regiões físicogeográficas) em cujos limites a influência da rotação "continente/oceano" permanece como início crítico para a posterior diferenciação do espaço terrestre, enquanto aumenta a importância da rotação interna e manifestam-se as ligações de faixas zonais (verticais) (SOTCHAVA, 1977, p.24).

(...) o espaço de menor geócoro regional deverá incluir uma diversidade mínima de geótopos; o suficiente, apenas para identificar as peculiaridades regionais da localidade (SOTCHAVA, 1977, p.22).

Bertrand (2004, p.142) na análise da paisagem descreveu o discernimento das 
hierarquias como unidades homogêneas, como 'encaixadas' umas nas outras, cujo sentido exato fica difícil de esclarecer. Mas em nenhum momento parece defender discernimentos, classificações e funcionalidades rígidas, ou, a imposição rígida de uma hierarquia sobre a outra. Parece mais expressar heranças funcionalistas da geografia francesa - de funções se entrelaçando:

As classificações elementares - cada disciplina especializada no estudo de um aspecto da paisagem se apoia em um sistema de delimitação mais ou menos esquemático formado de unidades homogêneas (ao menos em EXEMPLOS relação à escala considerada) e hierarquizadas, que se encaixam umas nas outras (BERTRAND, 2004, p.142). (...) Existem, para cada ordem de fenômenos, "inícios de manifestações" e de "extinção" e por eles pode-se legitimar a delimitação sistemática das paisagens em unidades hierarquizadas. Isto nos leva a dizer que a definição de uma paisagem é função da escala. No seio de um mesmo sistema taxonômico, os elementos climáticos e estruturais são básicos nas unidades superiores (G. I a G. IV) e os elementos biogeográfico (2004, p.148). (...) O sistema de evolução se define por uma série de agentes e de processos mais ou menos bem hierarquizados. Sem querer desenvolver aqui essa questão, podem ser distinguidos agentes naturais (climáticos, biológicos, etc...) que determinam processos naturais (ravinamentos, pedogênese, dinâmica ecofisiológica...) e agentes antrópicos (sociedades agropastoris, florestais...) dos quais dependem os processos antrópicos (desmatamento, incêndio, reflorestamento) nas unidades inferiores (G. V a G. VIII) (BERTRAND, 2004, p.144).

As propostas de Sotchava (1977, p.09) pautaram-se nas considerações do biólogo Bertalanffy (1973, 351p.), pela Teoria Geral dos Sistemas, que tratou as propriedades e funcionalidades hierárquicas como fundamentais (BERTALANFFY, 1973, p.49). Contudo, o biológo austríaco também não se aprofundou na discussão, por exemplo, com respeito às conexões e influências entre os níveis escalares. Bertalanffy (1973, p.49) comentou, no entanto, que concebia os princípios da ordem hierárquica a partir da concepção de Holon de Arthur Koestler, cujas flexibilidades entre os níveis hierárquicos vêm sendo utilizadas atualmente como recorro para explicar os processos de autoorganização. Na Geografia esta teoria já foi utilizada por Haigh (1987, p.181-192) no estudo da paisagem. Haigh (1987) discorreu que as hierarquias poderiam ser consideradas como propriedades sinergéticas dos sistemas abertos que expressariam um balanço entre os elementos locais, a partir de uma auto-afirmação no coletivo, numa inerente tendência integrativa em cadeia de inter-relações. Estas inter-relações e fluidez energética dos elementos e dos diversos níveis emergenciais causariam uma tensão entre as cadeias, de maneira que, as diferenças de impactos e mudanças adaptativas em diferentes níveis poderiam, muito bem, resultar em rupturas e transformações, com reestruturações funcionais, materiais das cadeias hierárquicas em outros níveis (HAIGH, 1987, p.190).

Pela Complexidade as hierarquias do geossistema parece se assemelhar às considerações de Haigh (1987, p.181-192). Deixam de ser simplesmente vinculadas às totalidades naturais objetivas e se tornam as relações discernidas pelo pesquisador como pertencente à interação do sistema em questão; e envolvendo a presença e interinfluência de múltiplas dimensões e domínios, inclusive a noosfera e o sócio-cultural. Dizendo isso não se quer afirmar que fisionomias com homogeneidades espaciais passíveis de delimitações métricas, não sejam observadas na Paisagem nas diversas escalas - dos geotopos às macro-zonas -, e nem de que os processos, e características de interações, não mudem de natureza conforme muda a escala da grandeza espaçotemporal. Mas sim que, da mesma forma que as totalidades perdem suas realidades 
concretas e se tornam puramente 'relações', as hierarquias do geossistema deixam de ter manifestação fixa e se tornam decorrentes das interações que também são estabelecidas a partir do local, e não somente subjugadas pela totalidade; mas sim, participando de processos interescalares, de relações, inclusive com as totalidades, ou globalidades.

Convém lembrar que os limites espaciais, por si só, não esgotam o jogo de relações e processos em uma manifestação geográfica, mas sim é uma de suas expressões. Assim, as expressões morfológicas na paisagem refletem espacialmente esse jogo de relações entre os sistemas complexos locais que se ligam a interações que se interpenetram pelas escalas de diferentes grandezas espaçotemporais; e, por isso, os limites não pode ser fator que restrinja demais a visualização e tratamento das relações.

Outra repercussão para a concepção e discernimento das hierarquias pela Complexidade se dá pela interação entre os domínios de manifestação causal e simbólico, com o causal interagindo com o simbólico e viceversa. Não se pode mais considerar um sem o remetimento ao outro, inclusive entre as escalas indivíduo/sociedade, mesmo que for apenas em relação aos discernimentos dos problemas, fatores e processos de uma pesquisa. $\mathrm{Na}$ perspectiva organizacional as hierarquias $e$ domínios tornam-se discerníveis, e não podem mais se ausentar da influência do sujeito que fez a seleção (DUTRA-GOMES, 2009). Na funcionalidade do geossistema há tanto sujeições, quanto liberdades, tanto ordem, quanto desordem, de forma que a interação entre as escalas (local, global) e esferas de ações (causal, simbólico) deixam de ter tons impositivos de sujeição legislativa de umas sobre as outras (como feitas pelo naturalismo), e tornam-se, entre si, em maior e menor grau, fluidas e interinfluentes; nos termos morinianos numa relação antagônica-concorrente-complementar entre ritmos escalares e de domínios de manifestação (individual, social, causal, comportamental).
Pela leitura aqui realizada, neste jogo entrelaçado e misturado pelas escalas de relações entre elementos, domínios e forças, as unidades e hierarquias do geossistema, novamente destacando, deixam de ser objetivas e passam a se referir à níveis organizacionais com ritmos espaçotemporais de interação discernidos (por um sujeito) na diversidade dos processos espaciais. Cada ritmo de interação entre elementos e forças detém sua própria e singular espaçotemporalidade, que varia de acordo com a natureza dos elementos e intensidade das trocas, podendo se referir a relações com espaçotemporalidades de grandes extensões, milenares, ou de milhões de anos e grandes áreas, como dos sistemas geomorfológicos e, também referir-se a ritmos efêmeros, como ritmos de fluxo de pessoas num centro urbano, que varia de acordo com as horas do dia e os locais da cidade.

$\mathrm{Na}$ interação dos ritmos a Crise Ambiental serve de exemplo para as perturbações e desequilíbrios que os ritmos da modernidade impõem aos ritmos naturais nas diversas escalas; com enchentes, desmoronamentos, poluições, patologias coletivas, como epidemias, ansiedades, expressando emergências advindas das intervenções e adaptação dos componentes e das forças à situação de reajuste provocadas pelas mudanças nas condições ambientais (desmatamento, impermeabilização, despejo de dejetos). Longe de sugerir a separação dos sistemas naturais e humanos, ou colocar os sistemas humanos somente como desequilibradores dos sistemas naturais, isso destaca as suas interpenetrações e interinfluências. Isso porque há de se considerar que pela Teoria da Complexidade neste complexo de relações locais/globais e causais/simbólicas, de ritmos, ocorrem essas emergências e processos auto-organizados, cuja natureza de relações ao nível global transcendem qualitativamente a escala da interação de seus componentes, que ficam conectados a ele, numa relação de subordinações e autonomias. No caso da emergência tanto sua manifestação quanto 
sua qualidade emergencial são imprevisíveis no âmbito das partes. Ou seja, a interação entre as escalas (totalidade/ partes) se tornam mais fluidas, imprevisíveis e seus contornos menos rígidos.

Outro aspecto importante que foi destacado pela Complexidade foi o realce dos mecanismos e relações internas na configuração das organizações e macrosistemas. Nas relações de um sistema consigo mesmo e seu ambiente, o nível de sua totalidade não guia soberanamente as partes, mas é justamente as relações internas ao sistema é que vai garantir a estabilidade para que o nível global se manifeste. Ou seja, mesmo que as emergências sejam imprevisíveis para com as partes, estas são o substrato necessário para que a totalidade se manifeste; e não é um substrato passivo. Nesta interação entre escalas as forças contextuais como as climáticas e da evolução da sociedade e estrutura urbana, ainda continuam influenciando o local em acordo com os seus ritmos espaçotemporais e condicionamento das relações (e que é característico de qualquer organização sistêmica), mas estas forças são vividas, por exemplo, sua adaptação, à nível local, à nível de interações locais, e não somente por subversões do todo sobre as partes. E os diversos domínios (como os individual, simbólicos, culturais) podem muito bem chegar a interagir e influir em escalas causais espaçotemporalmente maiores, como regionais, continentais e mundiais - a discussão sobre as mudanças climáticas bem expressam isso, ou seja, as influências das intervenções humanas, no caso, da cultura ocidental, sobre os sistemas causais ambientais com funcionalidades em macro e mesoescala.

O diálogo entre os conhecimentos no modelo Geossistêmico vêm para lidar com esta multiplicidade de domínios de manifestações e ritmos escalares presentes e influentes nos processos geográficos. Um dos desafios agora será reconhecer as aberturas para esse diálogo, e outro será desenvolver a sua operacionalidade. Conforme sugere Brown (2004, p.367-381) o reconhecimento das incertezas na Ciência pode ser uma dessas aberturas. Elas encontram-se presentes nas diversas esferas: - nos processos físicos causais, - na abstração e simplificação do observador, - nos encerramentos operacionais dos modelos, - nos tratamentos de processos que são multiescalares, - nas influências de domínios (como o comportamental, espírito, cultural, social, político) com funcionalidades pouco, ou mesmo não-redutíveis aos termos fisicalistas e formais dos modelos científicos. A consciência das incertezas envolvidas na reflexão e prática científica poderão servir de aberturas para os diálogos com outros conhecimentos - de técnicas, métodos a epistemologias e filosofias caso sejam necessários requerer novas informações sobre o sistema; informações que de repente possam ser melhor colhidas com outras condutas de reflexão e prática que não a do modelo fisicalista geossistêmico. Daí a congruência com as proposições de Monteiro (1978) de confronto com modelos paralelos, aqui concebido de forma ampla, envolvendo, inclusive, outras epistemologias e filosofias.

Na mesma direção é a sugestão de Durand-Dastes (1991, p.313) na necessidade de reconhecer que nos modelos conceituais, de acordo com a abordagem, existem resíduos incompreensíveis incontornáveis, que podem, em termos duais, serem exemplificados nos resíduos qualitativos nos modelos quantitativos e viceversa, ou os resíduos simbólicos nos modelos causais e vice-versa. O autor destaca também a necessidade de a modelagem incluir fatores como as aleatoriedades, bifurcações conforme forem reconhecidos como pertinentes no sistema de relações estudados e conforme forem sendo observados e refletidos nos resultados. O diálogo entre os conhecimentos, na fluidez das hierarquias e domínios do geossistema, viria tanto para lidar com os resíduos incompreensíveis em busca de perspectivas conciliatórias e complementares, quanto para a inserção de informações de fatores considerados pertinentes não cobertas pelos modelos. Tal situação de esforço para dialogar abordagens remete à problemática escalar tratada por Schumm \& Lichty (1973, p.44) na Geomorfologia. 
Schumm \& Lichty (1973, p.44), inseridos na perspectiva sistêmica, buscaram justamente resolver a controvérsia que dividia o campo geomorfológico numa dicotomia de mútuas exclusões entre as abordagens escalares: a funcional e a histórica-evolutiva. A abordagem funcional tem como representantes modernos as proposições de A. Strahler e R. Chorley, e a abordagem histórica-evolutiva é representada principalmente pelas proposições de W. M. Davis com o "Ciclo da Erosão". Schumm \& Litchy (1973, p.43-62) procuraram demonstrar que nos estudos processuais, em perspectiva sistêmica, deveria-se, na verdade, procurar relatar os níveis de causalidades envolvidas no fenômeno, para que, com isso, pudesse-se distinguir a forma, ou abordagem, mais adequada para se descrever e vislumbrar a evolução do sistema. Os autores relevaram que a distinção entre causa e efeito no modelado das formas de relevo dependeria do período de tempo envolvido e da grandeza espacial do sistema geomórfico em consideração. A causalidade poderia, assim, muito bem variar em dependência do tempo e do tamanho (espaço) da área de pesquisa considerada grandes áreas/longos tempos, pequenas áreas/curtos tempos - de forma que, desde que se alterassem estas dimensões, as relações de causa e efeito poderiam ser obscurecidas e até mesmo revertidas, de maneira que a descrição do sistema, se funcional ou histórica-evolutiva, poderia muito bem variar de acordo com a escala adotada. Isso por que os fatores que determinariam, por exemplo, o caráter das formas de relevo (Clima, Geologia, Vegetação, Intenvenções Antrópicas), poderiam ser ambos, tanto variáveis dependentes, quanto variáveis independentes, de acordo com os limites estabelecidos de mudanças no tempo e no espaço considerados. Por exemplo, quando se considera pequenas áreas e curtos tempos, as variáveis Clima e Geologia (que correspondem a grandes áreas e longos tempos) poderiam ser consideradas independentes, ou seja, não pertinentes em minúcias para o estudo dos processos locais, como uma desestruturação pedológica, e desmatamento local, podendo, neste caso, utilizar a abordagem funcional. Mas se considerasse grandes áreas e longos tempos, o relevo em pequena escala (grandes dimensões) iria mudando lentamente e respondendo às variabilidades e mudanças climáticas das Eras geológicas, neste caso, as variáveis locais (como o desmatamento) tornariam-se independentes, ou não influente em minúcias na escala de causalidade adotada, e o clima e a geologia tornariam-se fatores dependentes para o estudo do processo; neste caso, a abordagem históricoevolutiva tornaria-se mais adequada e adaptada. Os autores já destacavam que as duas abordagens não precisariam, assim, ser tratadas como antagônicas, mas complementares para o estudo global do fenômeno geomorfológico; o contexto da Complexidade vai reafirmar tal necessidade para as diversas dualidades (ontológicas e epistemológicas) vividas como dicotômicas na modernidade.

Sobre essa problemática tratada por Schumm \& Litchy (1973), o contexto da Complexidade gerou na Geomorfologia, com Rhoads (2006, p.14-300), a revisão de aspectos basilares da manifestação e estudo dos processos geomorfológicos. Rhoads (2006) discorreu que nas abordagens funcionais as heranças de uma concepção mecanicista voltada ao equilíbrio ainda são muito presentes, havendo, portanto, a pertinência da revisão da concepção de dinâmica (de fundos mecanicista) para uma concepção mais fundamentalmente processual que inclua os entendimentos dos sistemas complexos (RHOADS, 2006, p.14-300). De acordo com Rhoads (2006) essa revisão repercute em aspectos primordiais como: (1) a ultrapassagem e eliminação da dicotomia entre uma pesquisa pautada no processo (funcionais, a-históricas, padrões gerais) e as pesquisas geo-históricas de fundo empírico-descritivo, em favor de uma perspectiva organizacional, que enfatizou o desvendamento dos mistérios envolvidos nas dinâmicas morfogenéticas inerentes às interações dos sistemas naturais complexos (SPEDDING, 1997, p.261-265). (2)Houve a acomodação da explanação qualitativa para a descrição dos fenômenos, dando maior liberdade 
aos pesquisadores para recorrer às considerações interpretativas e históricas. As manifestações e estudos geomorfológicos tornam-se fundamentalmente espaçotemporalmente localizados (singulares).

(3) Flexibilizou-se as hierarquias das escalas espaço/temporais. Dissolveu-se a rigidez fixada entre os níveis de causalidade, propostas por Schumm e Litchy, sobre as variáveis dependentes, independentes e irrelevantes dos processos e formas. Os 'aprisionamentos' temporais não poderão mais ser rigidamente vividos, as influências entre as escalas, grandes áreas-longos tempos e pequenas áreas-curtos tempos, poderão até ser 'relaxadas', no sentido, de dar menos peso sobre suas influências, mas não deverão mais ser ignoradas completamente. Essa perspectiva enfatizou a pertinência de comparações e complementos entre métodos alternativos, somando entendimentos das abordagens dinâmicas-funcionais e geo-históricas para uma mais completa compreensão dos fenômenos (LANE \& RICHARD, 1997, p.249-260). (4) E a detenção, potencialmente reconhecida, para ligar os estudos geomorfológicos aos de Geografia Humana, mas, para isso destaca-se a Geografia como um todo para o diálogo entre os conhecimentos.

Neste sentido, no caso do Geossistema, em áreas antropizadas o diálogo pode envolver métodos e epistemologias utilizadas na Geografia Humana, conforme, por exemplo, os domínios e hierarquias humanas, forem considerados como pertinentes de serem estudados por tais métodos, e inseridos como dados no modelo, em alguma problemática discernida- da temática da Geografia Física. A operacionalidade do diálogo entre conhecimentos a partir da abordagem e modelo geossistêmico é uma construção que atualmente se encontra no assentamento dos alicerces. Em Monteiro (1978, p.61) houve a sugestão de confrontar modelos paralelos como forma de flexibilizar a análise da relação homem e natureza. Do quadro das influências antrópicas só entrariam os fatos materializados no ambiente, como esforço de evitar o reducionismo do fenômeno humano no modelo. Pela leitura realizada, via Complexidade, na atual situação o modelo permanece 'fisicalista' e voltado aos estudos ambientais (é importante deixar isso claro), mas é complementado pela presença do simbólico, do imaginário, no físico-causal, já que são vistos como inerentes e pertencentes (emergentes) à dinâmica dos Geossistemas 'complexos'. O tratamento do simbólico pode muito bem se dar não apenas com base na materialização, mas, por exemplo, pelo inquérito das intenções e finalidades, ou vivências e imaginário dos agentes (moradores, administradores), como forma de obter meios de previsão (restrita) de comportamento, argumentos para a decisão e resolução dos problemas ambientais. A utilização de outras epistemologias e modelos para o inquérito não apenas dos aspectos simbólicos, mas para as manifestações rítmicas, por exemplo, que requererem abordagens específicas, poderá conduzir o modelo Geossistema na direção da hibridez; e cuja operacionalidade se afirmará em decorrência dos testes na realidade.

\section{CONSIDERAÇÕES FINAIS}

Considerou-se aqui o Geossistema como um Sistema Singular Complexo. Tanto pela proposta de Monteiro $(1978,43 p$.) quanto pelos entendimentos da Complexidade. Nesta concepção o humano e o natural são partes integrantes de um mesmo jogo de relações complexas e múltiplas em domínios e dimensões de manifestações; e neste jogo incluem como fatores o simbólico, o imaginário, as relações sociais, políticas, econômicas. O humano não é apenas fator desequilibrador mas também participa como parte integrante do Geossistema, e inclusive, também gera processos regeneradores e benéficos no sistema conforme Monteiro (1978) já discorria.

O modelo continua a ser fisicalista e voltado para os estudos ambientais, mas o social, cultural, simbólico, imaginário, as intencionalidades e finalidades são emergências, e não antagônicas ao físico, retroagindo e influenciando sobre ele. Nesta leitura de Geossistema, o físico e simbólico pertencem à 
uma mesma dinâmica organizacional geossistêmica. Mesmo ainda se referindo aos estudos ambientais, nesta perspectiva, há a necessidade de se buscar, conforme a necessidade e objetivos, o cultural, o social, o econômico no Geossistema; por exemplo, na percepção ou vivência de impactos ambientais, ou em processos de segregação espacial que intensifica problemas ambientais. Nesta direção a proposta de Monteiro (1978, 43p.) destaca a necessidade de modelos paralelos para mais adequadamente tratar as respectivas temáticas; e, pelo que foi discutido pela Complexidade, há na verdade a necessidade de dialogar formas de conhecimento (epistemologias, teorias, métodos, técnicas).

Pela Complexidade o Geossistema parece não ser uma totalidade objetiva, mas uma definição arbitrária do pesquisador, de acordo com o foco, objetivos, problemática e contexto sociocultural. As morfologias e homogeneidades observadas na paisagem, não caracterizam, por si só, sua realidade objetiva, pois não esgotam as relações e escalas envolvidas, logo parecem não serem suficientes para finalizar a definição empírica do Geossistema.

Nesta direção, pela leitura realizada, via Complexidade, as unidades (geótopo, geofácies) e as hierarquias do geossistema deixam de ser objetivas e passam a se referir a ritmos espaçotemporais de interação, ou um conjunto de relações discernidas pelo pesquisador em determinada escala (seja meso, macro, micro, topo). Considerando que estas relações são tratadas como detendo tanto padrões, ordenações e homogeneidades, quanto singularidades, aleatoriedades e heterogeneidades, preferiu-se falar de ritmos (BERGÉ et al., 1996, 301p.) para se referir sobre dinâmicas de relações complexas (nos termos da Complexidade). Cada ritmo de interação entre elementos e forças detém sua própria e singular espaçotemporalidade, que varia de acordo com a natureza dos elementos e intensidade das trocas, podendo se referir a relações com espaçotemporalidades nas e pelas diversas escalas. A adoção da noção de Ritmo influencia- se também na proposta de Monteiro (1991, 233p.) que é a precursora nacional na adoção desta noção em diálogo ao contexto dos sistemas complexos; no caso, voltada para a análise do clima, em sua proposta de Análise Rítmica.

O diálogo entre os conhecimentos no modelo Geossistêmico vem para lidar com esta multiplicidade de ritmos presentes e influentes nas e pelas escalas; bem como dos domínios humanos e naturais presentes nos geossistemas. No exemplo histórico da proposta de Schumm \& Litchy (1973, p.43-62), e na sua revisão por Lane \& Richard (1999, p.249-260), propõe-se o diálogo entre as abordagens geohistóricas e funcionais para se realizar uma análise multiescalar em geomorfologia, aqui o diálogo de abordagens vem para lidar tanto com a questão escalar, quanto dos domínios (humanos e naturais) envolvidos na trama. Em áreas antropizadas o diálogo pretende envolver métodos e epistemologias utilizadas na Geografia Humana. O desafio agora será reconhecer as interações entre as escalas, entre os ritmos, e reconhecer as aberturas para o diálogo entre os conhecimentos, de forma aprimorar a operacionalidade do modelo. As incertezas presentes na seleção, definição e operacionalização dos modelos, bem como os resíduos qualitativos incompreensíveis nos modelos quantitativos, e vice-versa, são algumas das 'brechas' reconhecidas para se esclarecer e embasar as aberturas necessárias para o diálogo.

\section{REFERÊNCIAS}

ALLEN, P. M. Towards a new science of complex systems..In: The Science and Praxis of Complexity. Contributions to the Symposium held at Montpellier, France, 9-11 May 1984. New York: Ed. The United Nations University, 1985, 384p., pp.268-297.

BERGÉ, P., POMEAU, Y., DUBOIS-GANCE, M. Dos ritmos ao caos. São Paulo : Editora da UNESP, 1996, 301p.

BERTALANFFY, L. V. Teoria Geral dos Sistemas. Petrópolis : Editora Vozes, 1973, 351p. 
BERTRAND, G. Paisagem e geografia física global: esboço metodológico. Caderno de ciências da terra, São Paulo, n.13, 27p., 1972.

BERTRAND, C., BERTRAND, G. Uma Geografia Transversal - e de travessias - (O meio ambiente através dos territórios e das temporalidades. Maringá : Ed. Massoni, 2002, 361p.

BROWN, J. D. Knowledge, uncertainty and physicial geography: towards the development of methodologies for questioning belief. Transactions of the Institute British Geographers, New Series, 29, pp.367-381, 2004.

CHAPURA, M. Scale, causality, complexity and emergence: rethinking scale's ontological significance. Transactions Institute British Geographers, 34, p.462-474, 2009.

CHRISTOFOLETTI, A. Potencialidades das abordagens sobre os sistemas dinâmicos para os estudos geográficos: alerta para uma nova fase. Geografia, Rio Claro : vol. 13(26), 149-151, 1988.

CLIFFORD, N. J. Models in geography revisited. Geoforum, 39, 2008, pp.675-686.

CULLING, W. E. H. Equifinality: modern approaches to dynamical systems and their potential for geographical thought. Transactions of the Institute British Geographers, London, 12 : pp.57-72, 1987.

CULLING, W. E. H. A new view of the landscape. London: Transactions of the Institute British Geographers, London : 13, p.345-360, 1988.

DATTA, D. P., RAUT, S. The arrow of time, complexity and scale free analysis. Chaos, Solitons and Fractals, 28, pp.581-589, 2006.

DURAND-DASTÈS, F. La notion de chaos et la géographie quelques réflexions. L'Espace géographique, n.4, pp.311-314, 1991.

DUTRA GOMES, R. Ontologia Sistêmica: construção do espaço e perspectiva ambiental. GEOUSP, 25, pp.109-122, 2009.

DUTRA-GOMES, R. Geografia e Complexidade: das diferenciações de áreas à Nova Cognição do Sistema Terra-Mundo. 06/2010, Tese de Doutorado, Instituto de Geociências, UNICAMP/Campinas.

DUTRA-GOMES, R. A matriz espacial moderna: das diferenciações de áreas de Hartshorne à Teoria da Complexidade: O caso da expansão do aeroporto internacional de Viracopos/CampinasSP. Maio de 2012, Relatório de PósDoutoramento FAPESP - IG/UNICAMP, Campinas.

DUTRA-GOMES, R. VITTE, A. C. Geografia e Complexidade: das diferenciações de áreas à construção epistemológica da Geografia na América Latina. Mercator, 2015, 12p. (submetido).

DUTRA-GOMES, R., VITTE, A. C. Geografia e Complexidade pelas diferenciações areais de Hartshorne. Geosul (UFSC), v. 29, p. 89-130, 2014.

DUTRA-GOMES, R., VITTE, A. C. A Geografia Física e o objeto complexo: algumas flexibilizações do processual. Geosul, v. 26, n.50, p.08-38, 2010

GIDDENS, A. As consequências da modernidade. São Paulo : Ed. UNESP, 1991, 177p.

HAKEN, H. Synergetics: An approach to complex dynamic systems. Advances in Applied Probability, Vol.14, №2, Jun, p.197-197, 1982.

HAIGH, M. J. The Holon: Hierarqhy Theory and Landscape Research. Catena Supplement 10, Braunschweig, p.181-192, 1987.

LANE, S. N., RICHARDS, K. Linking river channel form and process: time, space and causality revisited. Earth Surface Processes and Landforms, vol.22, p.249-260, 1997.

LE MOIGNE, J. La modélisation des systèmes complexes. Paris : Ed. Dunod, 178p., 1990.

LEMPERT, R. J. A New Decision Sciences for Complex Systems. In: Proceedings of the National Academy of Sciences of the United States of America, 2002, Vol. 99, No. 10, Supplement 3: Arthur M. Sackler Colloquium of the National Academy of Sciences. Sackler Colloquium on Adaptive Agents, Intelligence, and Emergent Human Organization: Capturing Complexity though Agent-Based Modeling, May 14, p. 73097313.

MALANSON, G. P. Considering Complexity. Annals of the Association of American Geographers, 89, p.746-753, 1999.

MANSON, S. M. Does scale exist? An epistemological scale continuum for complex human-environment systems. Geoforum, 39, p.776-788, 2008. 
MONTEIRO, C. A. F. Derivações antropogênicas dos geossistemas terrestres no Brasil e alterações climáticas. Perspectivas urbanas e agrárias ao problema da elaboração de modelos de avaliação. In: ANAIS DO SIMPÓSIO SOBRE A COMUNIDADE VEGETAL COMO UNIDADE BIOLÓGICA, TURÍSTICA E ECONÔMICA. 1978, ACIESP, 15. Secretaria da Cultura, Ciência e Tecnologia. Academia de Ciências do Estado de São Paulo, 43p.

MONTEIRO, C. A. F. (Coordenador) Qualidade Ambiental na Bahia: Recôncavo e regiões limítrofes. Salvador: Centro de Estudos e Informações (CEI), Secretaria de Planejamento, Ciência e Tecnologia (SEPLANTEC), 1987, 48p. (il.) MONTEIRO, C. A. F. Clima e excepcionalismo: Conjecturas sobre o desenvolvimento da atmosfera como fenômeno geográfico. Florianópolis : Ed. da UFSC, 1991, 233p.

MONTEIRO, C. A. F. Geossistema: a história de uma procura. São Paulo.: Contexto, 2001, 127p.

MORIN, E. On the definition of complexity. In: The Science and Praxis of Complexity. Contributions to the Symposium held at Montpellier, France, 9-11 May 1984, New York: The United Nations University, 1985, 384p., p.6268.

MORIN, E. O método. Vol. 1 - A natureza da natureza. Porto Alegre : Sulina, 2002, 480p.

MORIN, E. LE MOIGNE, J. L. A inteligência da complexidade. São Paulo : Ed. Peirópolis, 2000, $263 p$.

MORIN, E., LE MOIGNE, J. L. A inteligência da Complexidade - Epistemologia e Pragmática. Lisboa : Instituto Piaget, 2009, 527p.

O' SULLIVAN, D. Complexity science and human geography. Transactions of the Institute British Geographers. New Series, 29, p.282-295, 2004.

PENTEADO ORELLANA, M. Metodologia integrada no estudo do meio ambiente. Geografia, Rio Claro : 10(20), p.125-148, 1985.

PHILLIPS, J. D. The end of equilibrium? Geomorphology, Vol. 5, Issues 3-5, August p.195201, 1992.

PRIGOGINE, I. The philosophy of instability. Futures, August, p.396-400, 1989.
PRIGOGINE, I., STENGERS, I. A nova aliança. Brasília : Editora da UnB, 1991, 247p.

RHOADS, B. L. The Dynamic Basis of Geomorphology Reevisioned. Annals of the Association of American Geographers, 96 (1), p.14-30, 2006.

ROUGERIE, G., BEROUTCHACHVILI, N. Géosystèmes et Paysages. Bilan et méthodes. Paris : Ed. Armand Colin Éditeur,1991, 302p.

RUELLE, D. Acaso e Caos. São Paulo : Editora da UNESP, 1993, 224p.

SCHUMM, S. A., LICHTY, R. W. Tempo, espaço e causalidade em geomorfologia. Notícias Geomorfológicas, Campinas, 13 (25) : p.43-62. Jun.1973.

SCIENCE, magazine. Complex Systems, 1999, 2 April, Vol.284, Issue 5411, p.1-212.

SHŪHEI, A (Org.). The Science and Praxis of Complexity. Contributions to the Symposium held at Montpellier, France, 9-11 May 1984, New York: Ed. The United Nations University, 1985, 384p.

SOTCHAVA, V. B. O estudo de geossistemas. Métodos em Questão. São Paulo : IG-USP, n.16, 52p., 1977.

SOTCHAVA, V. B. Por uma teoria de classificação de geossistemas de vida terrestre. Biogeografia,USP, Instituto de Geografia, 24p., 1978.

SPEDDING, N. On Growth and Form in Geomorphology. Earth Surface Process and Landforms, Vol.22, p.261-265,1997.

TRENTIM, Gracieli; FERREIRA, Marcos César. Análise Direcional da Expansão Urbana de Cidades de Porte Médio: Uma aplicação da dimensão fractal. RA'E GA: o Espaço Geográfico em Análise, v. 33, p. 198, 2015

VITTE, A. C. Por uma geografia híbrida: ensaios sobre os mundos, as naturezas e as culturas. Curitiba : Editora CRV, 112p., 2011. 